\title{
Evaluation of anticancer activity of Melaleuka Alternifolia. (i. e. tea tree oil) on Breast cancer cell line (MDA MB)- An invitro study
}

\author{
Sujata Byahatti ${ }^{1, *}$, Chetana Bogar ${ }^{2}$, Kishore Bhat $^{3}$, Girish Dandagi $^{4}$ \\ ${ }^{1}$ Professor, ${ }^{2}$ Research Officer, ${ }^{3}$ Professor and HOD, ${ }^{1}$ Dept. of Oral Medicine and Radiology, ${ }^{2,3}$ Dept. of Microbiology and \\ Immunology, M M's N.G. Halgekar Institute of Dental Sciences and Research Centre, (Rajiv Gandhi University) Belgaum, \\ Karnataka, ${ }^{4}$ Professor and HOD, Dept. of Pulmonary Medicine, Belgaum Institute of Medical Sciences, Belagavi, Karnataka, \\ India
}

\section{*Corresponding Author:}

Email: sujatabyahatti78@gmail.com

\begin{abstract}
Introduction and Aims: According to Globocan 2012, India along with United States and China collectively accounts for almost one third of the global breast cancer burden. India is facing challenging situation due to $11.54 \%$ increase in incidence and $13.82 \%$ increase in mortality due to breast cancer during 2008-2012. The current treatment modality has issues of drug resistance and side effects. Many anticancer drugs currently used clinically have been isolated from plant species hence, investigation of plant species as a source of experimental therapeutic agents, in treating cancer is currently gaining a lot of importance. One such naturally available plant extract Melaleuka Alternifolia (TTO) which belongs to the family of essential oils is a very good antibacterial, antifungal, antiviral, antiprotozoal and anti-inflammatory agent. But currently there is a lot of importance has been given for its anticancer effect. Hence our aim is to evaluate anticancer activity of Melaleuka Alternifolia on Breast cancer cell line (MDA MB) by MTT assay an invitro method.

Material and Methods: Before the start of the study ethical clearance was obtained from Institutional Review Board. The cytotoxicity checked for Breast cancer cell line (MDA MB) and NIH 3T3 mouse fibroblasts which was used as a control in our current study. These cell lines were procured from National Centre for Cell Science (NCCS) Pune, India. 1. MTT solution preparation (stock solution): $5 \mathrm{mg}$ in $1 \mathrm{ml}$ of PBS. 2. Cell culture : The cell lines were maintained in 96 wells micro titer plate containing MEM media supplemented with $10 \%$ heat inactivated fetal calf serum (FCS), containing 5\% of mixture of Gentamicin (10ug), Penicillin ( 100 Units/ ml) and Streptomycin $(100 \mu \mathrm{g} / \mathrm{ml})$ in presence of $5 \% \mathrm{CO} 2$ at $37^{\circ} \mathrm{C}$ for $48-72$ hours. 3 . Cytotoxicity Assay: In vitro growth inhibition effect of test compound was assessed by calorimetric or spectrophotometric determination of conversion of MTT into Formazan blue by living cells.

Results: The results represent the mean of five readings. The $\mathrm{IC}_{50}$ value of tea tree oil for breast cancer cell line (MDA MB) after $48 \mathrm{hrs}$ was $25 \mu \mathrm{g} / \mathrm{ml}$. Spearmans rho's Correlation showed $\mathrm{P}$ value $<0.05$ indicating there was statistical significant results obtained when TTO was treated with breast cancer cell line (MDA MB) for 48 hrs incubation period.

Conclusion: TTO has a promising anticancer property against Breast cancer cell line (MDA MB) with its IC $50 \mathrm{value} 25 \mu \mathrm{g} / \mathrm{ml}$. Hence this TTO with its greater efficacy related to its anticancer activity can be brought to the level of clinical trials in the coming future.
\end{abstract}

Keywords: Cytotoxicity, MTT assay, MDAMB cell line, Tea tree oil.

\section{Introduction}

Globocan 2012 has reported that, India, United States and China together faces one third of the global breast cancer burden. India being the developing country which is facing breast cancer as a difficult circumstance due to sudden increase i.e. $11.54 \%$ in incidence and $13.82 \%$ in mortality from 2008-2012., ${ }^{1,2}$

Hence, the research for new therapeutic drugs that have great action towards cancer is one of the most interesting subjects in the field of natural products. Although, plants play a predominant role as a sophisticated traditional medicine systems, in the development of treatment for cancer. Plant-derived essential oils exert better therapeutic activity and have also demonstrated that their isolated major compounds may exhibit higher cytotoxic effect than the original plant. $^{3}$

Hence, the study which includes the naturally available products has been the single most successful strategy for the discovery of numerous new medicines used in anticancer therapy, and more than two thirds of the drugs used in cancer treatment come directly from natural products or are developed using knowledge gained from the activity of their ingredients. ${ }^{4,5}$

One such naturally available plant extract derived from Australian native plant Melaleuka Alternifolia i.e tea tree oil (TTO), invented by Penfold ${ }^{6}$ in the year 1920 has more than 100 components which has many medicinal properties.

Hence the aim of the current study was to evaluate the anticancer activity of Melaleuka Alternifolia, i.e. Tea tree oil (TTO) against Breast (MDA MB) cancer cell line and NIH3T3 cell line which was used as control, by in vitro method MTT Assay.

\section{Material and Methods}

Source of data: Before the start of the study ethical clearance was obtained by Institutional Review Board. We evaluated the anticancer activity of M.Alternifolia (i,.e.TTO) on breast cancer cell line (MDA MB). We 
received this commercially available Tea tree oil from Crystal aromatics New Delhi, imported from Australia with Refractive index 1.475 , at $25^{\circ}$ weight $/ \mathrm{ml}$ was $0.8850 \mathrm{gm} / \mathrm{ml}$. The cell lines which were procured from NCCS (National Centre for Cell Science), Pune, India. Then subjected for MTT Assay to assess the cell viability and cell cytotoxicity (Cell Lysis).

\section{MTT Assay}

1. MTT solution preparation (stock solution): $5 \mathrm{mg}$ in $1 \mathrm{ml}$ of PBS.

MTT (yellow dye) reduced by succinic dehydrogenase in the mitochondria of viable cells to purple formazan crystals. Formazan crystal production is directly proportional to the viable cells and inversely to the degree of cytotoxicity. When cells die, they lose the ability to convert MTT into formazan, thus color formation serves as a useful and convenient marker of only the viable cells.

2. Cell culture: The cell line used for the study were breast cancer cell line (MDA MB) (human) \& NIH3T3 (Mouse fibroblasts) procured from NCCS, Pune. The cell line then maintained in 96 wells micro titer plate containing MEM media supplemented with $10 \%$ heat inactivated fetal calf serum (FCS), containing 5\% of mixture of Gentamicin (10ug), Penicillin (100 Units/ ml) and Streptomycin $(100 \mu \mathrm{g} / \mathrm{ml})$ in presence of $5 \% \mathrm{CO}_{2}$ at $37^{\circ} \mathrm{C}$ for $48-72$ hours.

3. Cytotoxicity Assay: In vitro growth inhibition effect of test compound was assessed by calorimetric or spectrophotometric determination of conversion of MTT into "Formazan blue" by living cells. Remove the supernatant from the plate and add fresh MEM solution and treat with different concentrations of extract or compound appropriately diluted with DMSO. In the current study, 10, 20, 25, 30 and 50ul of the stock solution (10mg / $\mathrm{ml}$ prepared in DMSO) were added to respective wells containing 100ul of the medium. So, the final concentrations were 10, 20, 25, 30 and 50ug / ml. That means to say the various concentration of TTO used to evaluate its anticancer activity were $100 \%, 50 \%, 25 \%, 12.5 \%$, $6.25 \%, 3.125 \%, 1.562 \%, 0.781 \%, 0.390 \%, 0.195 \%$ respectively.

a. After $24 \mathrm{hrs}$ incubation at $37^{\circ} \mathrm{C}$ in a humidified atmosphere of $5 \% \mathrm{Co} 2$, stock solution of MTT was added to each well $(20 \mu 1,5 \mathrm{mg}$ per $\mathrm{ml}$ in sterile PBS) for further $4 \mathrm{hr}$ incubation. The process repeated after $48 \mathrm{hrs}$.

b. The supernatant carefully aspirated, the precipitated crystals of "Formazan blue' were solubilised by adding DMSO $(100 \mu \mathrm{l})$ and optical density was measured at wavelength of $570 \mathrm{~nm}$ by using LISA plus.

4. The results represent the mean of five readings. The concentration at which the OD of treated cells was reduced by $50 \%$ with respect to the untreated control.

Formula:

Surviving cells $(\%)=\underline{\text { Mean OD of test compound } \times 100}$ Mean OD at control

Principle of assay: This is a colorimetric assay that measures the reduction of yellow 3-(4, 5dimethythiazol-2-yl)-2,5-diphenyl tetrazolium bromide (MTT) by mitochondrial succinate dehydrogenase. The MTT enters the cells and passes into the mitochondria where it is reduced to an insoluble, coloured (dark purple) formazan product. The cells are then solubilised with an organic solvent (eg. DMSO, Isopropanol) and the released, solubilised formazan reagent is measured spectrophotometrically. Since reduction of MTT can only occur in metabolically active cells the level of activity is a measure of the viability of the cells. ${ }^{7}$

\section{Results}

Table 1: The various concentrations of TTO, Mean OD noted for breast cancer cell line (MDA MB) with Cell viability and cell inhibition(cell lysis)

\begin{tabular}{|c|c|c|c|c|c|}
\hline S. No. & Cell line & $\begin{array}{c}\text { MDA MB } \\
\text { Concentration }\end{array}$ & $\begin{array}{c}\text { Absorbance } \\
(\mathbf{n m})\end{array}$ & $\begin{array}{c}\text { \% cell } \\
\text { viability }\end{array}$ & \% cell lysis \\
\hline 1 & $\begin{array}{c}\text { MDA MB } \\
\text { After 48hrs }\end{array}$ & 100 & 0.264 & 40 & 60 \\
\hline 2 & & 50 & 0.284 & 43 & 57 \\
\hline 3 & & 25 & 0.333 & 50.45 & 49.54 \\
\hline 4 & & 12.5 & 0.335 & 50.75 & 49.24 \\
\hline 5 & & 6.25 & 0.342 & 52.8 & 48.18 \\
\hline 6 & & 3.125 & 0.354 & 53.63 & 46.36 \\
\hline 7 & & 1.562 & 0.357 & 54 & 45.90 \\
\hline 8 & & 0.781 & 0.369 & 55.9 & 44.09 \\
\hline 9 & & 0.390 & 0.375 & 56.8 & 43.18 \\
\hline 10 & & 0.195 & 0.392 & 59.3 & 40.60 \\
\hline Control & & 00 & 0.66 & & \\
\hline
\end{tabular}


Table 2: Spearman's rhos Correlation

\begin{tabular}{|l|l|l|}
\hline MDAMB & -1.000 & p-value $<0.05$; Significant \\
\hline
\end{tabular}

Graph 1: Scatter plot showing TTO concentration, Cell death and viability for MDA MB cell line
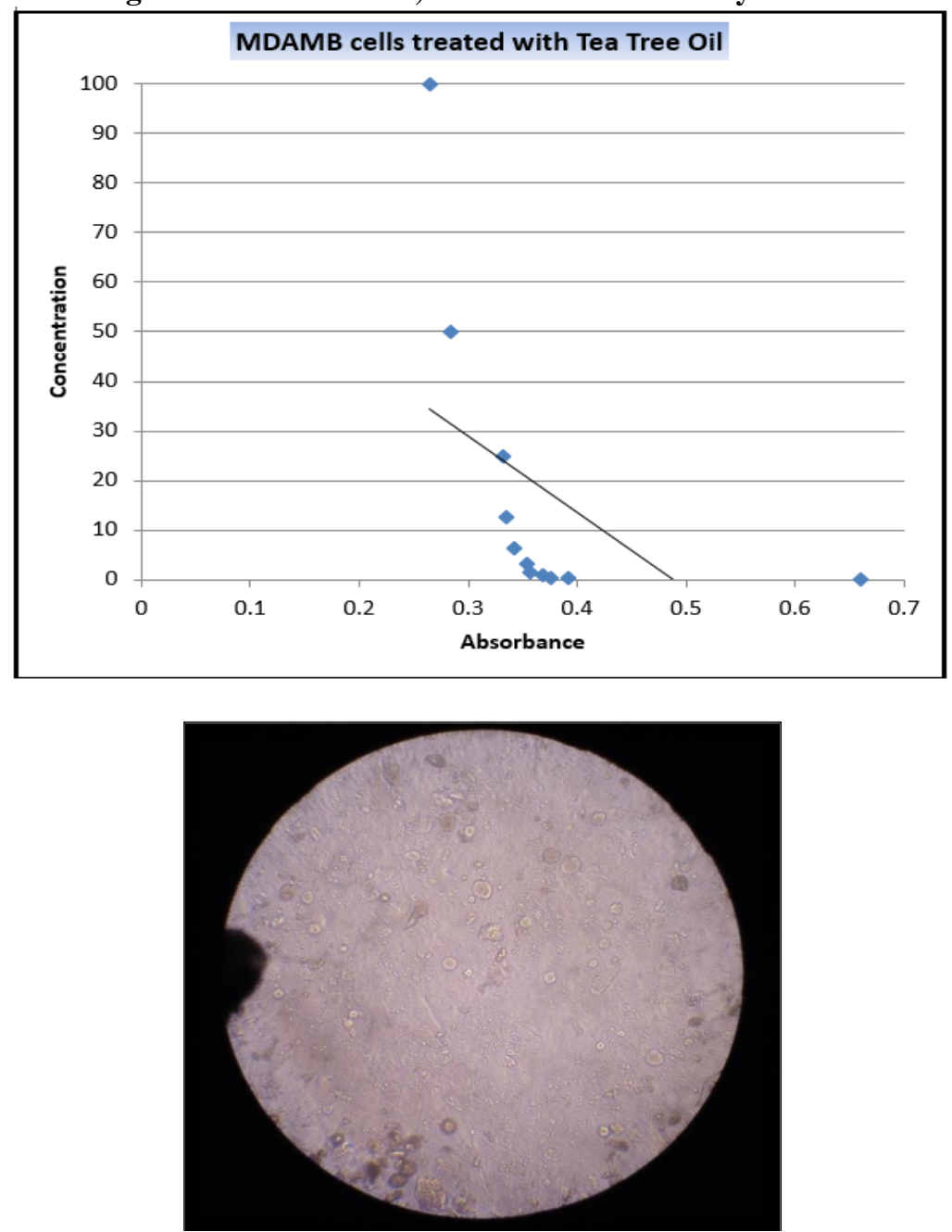

Fig. 1: TTO treated with MDA MB cancer cell line after $48 \mathrm{~h}$ showing cytotoxic effect with $50 \%$ cell lysis.

Table 2: The various concentrations of TTO, Mean OD noted for MDA MB cancer cell line with Cell viability and Cell Inhibition (Cell lysis)

\begin{tabular}{|c|c|c|c|c|c|}
\hline S. No. & Cell line & $\begin{array}{c}\text { NIH3T3 } \\
\text { Concentration }\end{array}$ & $\begin{array}{c}\text { Absorbance } \\
(\mathbf{n m})\end{array}$ & \% Cell lysis & \% Cell Viability \\
\hline 1 & NIH3T3 after 24hrs & 100 & 0.090 & 23.25 & 76.74 \\
\hline 2 & & 50 & 0.095 & 24.54 & 75.46 \\
\hline 3 & & 25 & 0.099 & 25.58 & 74.41 \\
\hline 4 & & 12.5 & 0.115 & 29.71 & 70.28 \\
\hline 5 & & 6.25 & 0.115 & 29.71 & 70.28 \\
\hline 6 & & 3.125 & 0.123 & 31.78 & 68.21 \\
\hline 7 & & 1.562 & 0.126 & 32.55 & 67.44 \\
\hline 8 & & 0.781 & 0.134 & 34.62 & 65.37 \\
\hline 9 & & 0.390 & 0.149 & 38.50 & 61.49 \\
\hline 10 & & 0.195 & 0.157 & 40.56 & 59.43 \\
\hline control & & 00 & 0.0 .387 & & \\
\hline
\end{tabular}


Graph 2: Scatter plot showing TTO concentration, Cell death and viability for NIH3T3 cell line

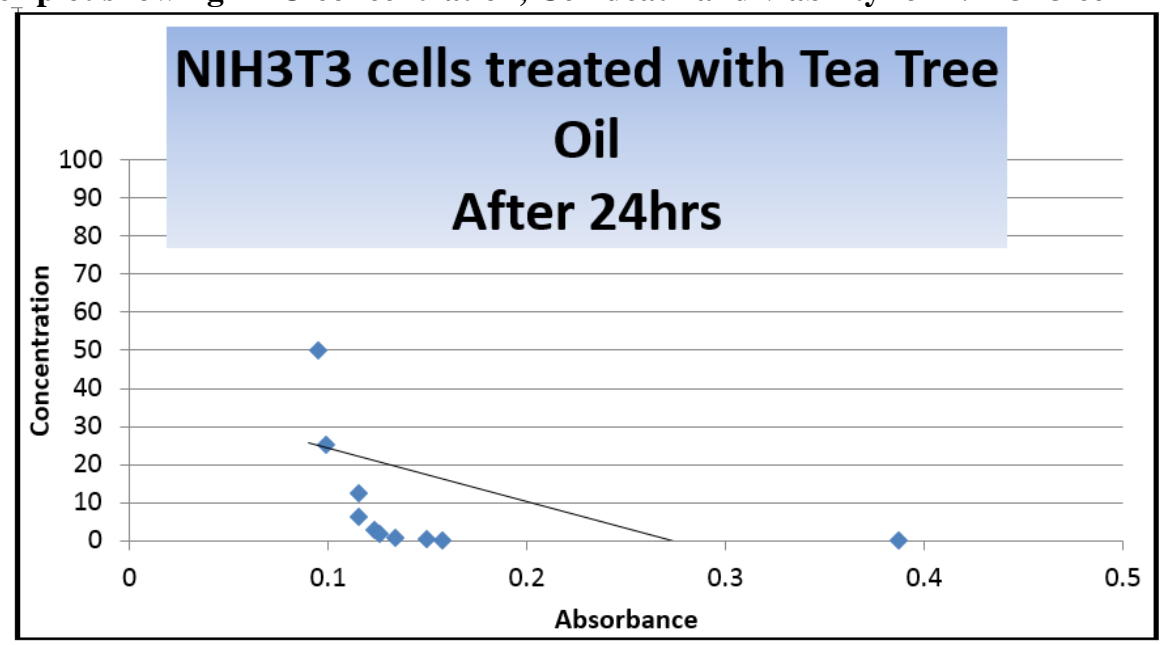

\section{Discussion}

In the current study, anticancer activity of TTO was used to evaluate its cytotoxic effect for Breast (MDA MB) Cancer Cell line and NIH3T3 mouse fibroblast cell line at $100 \%, 50 \%, 25 \%, 12.5 \%$, $6.25 \%, 3.125 \%, 1.562 \%, 0.781 \%, 0.390 \%, 0.195 \%$ concentrations respectively. This plant extract was used in serial dilution in triplicates which has shown that $50 \%$ of cell inhibition noted at the concentration of $25 \mu \mathrm{g} / \mathrm{ml}$. (Fig. 1). Spearman's rhos Correlation was showing statistical significant results with $\mathrm{P}$ value $<0.001$ when TTO was treated with MDA MB and NIH3T3 cell line. (Table 1, 2 \& Fig. 1). Scatter plot depicts TTO concentration, Cell death and viability for NIH3T3 Mouse fibroblast cell line (Graph 1, 2). After $24 \mathrm{hrs}$ incubation, the higher concentration of TTO, was showing 2-4 cell death but as the concentration reduced to $50 \%$ in serial dilution the excessive proliferation of cells was noted. Which indicates TTO was not toxic on NIH3T3 Mouse fibroblast cells which were used as control in our study.

Essential oils have wide range of bactericidal, fungicidal, antiparasitical and insecticidal properties. Hence they are widely used in pharmaceutical, sanitary, cosmetic, agriculture and food industries. Among medicinal properties anticancer activity is well documented. In the past ten years more than twenty plant families, which have given more than hundred essential oils which have been tested for more than twenty different types of cancers. ${ }^{8}$

Although, the cytotoxic effect caused by essential oils is already well known by number of in vitro studies. ${ }^{9}$

Hence, the search for new drugs that display activity against several types of cancer is playing prime role in natural medicine. ${ }^{10}$ The plant extracted essential oils are more concentrated and may exhibit higher toxicity than the original plant, which makes them to use at minimal concentration for results. ${ }^{11}$
The cytotoxicity level of TTO treated cultures was determined by decrease proliferation when compared to that in negative control. The genotoxic potential of TTO was assessed by the in vitro mammalian cell micronucleus and the chromosome aberrations (CA) tests. There were twenty-seven compounds were identified. Terpinen-4-ol (42.8\%), $\gamma$-terpinene $(20.4 \%)$, p-cymene $(9.6 \%), \alpha$-terpinene $(7.9 \%), 1,8$-cineole (3\%), $\alpha$-terpineol $(2.8 \%)$ and $\alpha$-pinene $(2.4 \%)$ were the major compounds of the oil sample. Results have demonstrated that TTO is not genotoxic in the tested concentrations, in various vitro mammalian cells. ${ }^{12}$

In another study in vitro anti-tumor activities of Melaleuca alternifolia (tea tree) oil (TTO) exhibited strong cytotoxicity towards human lung cancer cell line (A549), human breast cancer cell line (MCF-7) and human prostate cancer cell line (PC-3). The $\mathrm{IC}_{50}$ values obtained were $0.012 \%(\mathrm{v} / \mathrm{v}), 0.031 \%(\mathrm{v} / \mathrm{v})$ and $0.037 \%$ $(\mathrm{v} / \mathrm{v})$, respectively. ${ }^{13}$

The study also investigated some possible mechanisms underlying the in vitro antitumor activity of tea tree oil (TTO) on human and mouse breast cancer cells (MCF-7 and 4T1, respectively) and its cytotoxicity on fibroblasts (HFF-1) and on peripheral blood mononuclear cells (PBMCs). When high TTO concentrations $(\geq 600 \mu \mathrm{g} / \mathrm{mL})$ were used it showed a significant anticancer activity, reducing their cell viability and cell proliferation of MCF-7 and 4T1 cells. But, when lower TTO concentrations $(\leq 300 \mu \mathrm{g} / \mathrm{mL})$ were used it had no cytotoxic effect on PBMCs and HFF-1. Further, after $72 \mathrm{~h}$, TTO $(300 \mu \mathrm{g} / \mathrm{mL})$ induced higher cell proliferation in fibroblasts, which indicates non-cytotoxic effect in these cells. Hence this study provides a new perspectives on the potential use of TTO for the development of new alternative therapies to treat topically locally advanced breast cancer (LABC). ${ }^{14}$

Another study investigated the mechanism of carvacrol-induced cell death in MDA-MB 231 human metastatic breast cancer cells and demonstrated that this 
compound induced apoptosis in a dose-dependent manner; ${ }^{15}$ the mechanism of action of carvacrol may in fact be related to its antioxidant activity and not associated with a DNA-damaging effect.

Many plants derived essential oils have shown in vitro and in vivo antitumor activity among various studies. ${ }^{16}$ Although, many studies have shown the evaluation of possible mechanisms of action of these plant extracts, still the majority of literature present only preliminary screening data and therefore they do not describe any mechanism of action.

\section{Conclusion}

Many studies have shown that a large number of essential oils have significant anticancer activities, both on cell lines and on tumors in animals. Hence, the exploration of the antitumor properties of EO is now clearly a research axis that should receive the same interest than the more conventional chemotherapy treatments with synthetic anticancer agents. Hence, potential of essential oils for the treatment of cancer merits further exploration in the future.

As far as potential anticancer activity of essential oils is concerned, still there is no much information is available. Hence lot of research needs to be progressed in this regard. Efficacy of TTO as an anticancer agent with its $\mathrm{IC}_{50}$ Value in our study has shown better results than the other naturally available plant extracts from the previous literature. This variation in the result could be due to differences in the method and concentrations used from the previous studies. Hence, this $\mathrm{IC}_{50}$ value of TTO with its greater efficacy related to its anticancer activity can be brought to the level of clinical trials in the coming future.

\section{Acknowledgements}

I would like to thank Rajiv Gandhi University of health sciences for providing grant for conducting the above research. I would like to thank our beloved principal sir Dr.Ramakant Nayak, Head of the department of Oral Medicine and Radiology Dr Renuka Ammanagi, Dr Ravi Shirahatti, Head of the department of Public health Dentistry for support and encouragement.

\section{References}

1. Therlay J, Soerjomataram I, Dikshit R et al. Cancer incidence and mortality worldwide: sources, methods and major patterns in GLOBOCAN 2012. Int $J$ Cancer 2015;136:E359-86.
2. Therlay J, Shin HR, Bray F, Forman D, Mathers C, Parkin DM. Estimates of worldwide burden of cancer in 2008: GLOBOCAN 2008. Int J Cancer 2010;127:2893917.

3. Asif, M., Yehya, A. H. S., Al-Mansoub, M. A., Revadigar, V., Ezzat, M. O., Khadeer Ahamed, M. B., et al. Anticancer attributes of Illicium verum essential oils against colon cancer. South African Journal of Botany 2016;103:156-61.

4. J. C. L. R. Pita,A. L. Xavier, T. K. G. de Sousa et al., "In vitro and in vivo antitumor effect of trachylobane-360, a diterpene from Xylopia langs dorffiana," Molecules 2012;17(8):9573-89.

5. T. Efferth, "Cancer therapy with natural products and medicinal plants," Planta Medica 2010;76:1035-36.

6. Carson CF, Hammer KA, Riley TV Melaleuca alternifolia (tea tree) oil: a review of antimicrobial and other medicinal properties. Clin Microbiol Rev 2006;19:50-62.

7. Bagora B Bayala, IHN Bassole, R Scifo, C Gnoula et al. Anticancer activity of essential oils and their chemical components - a review. Am J Cancer Res 2014;4(6):591607.

8. Nakagawa, Y., Suzuki, T., Cytotoxic and xenoestrogenic effects via biotransformation of transanethole on isolated rat hepatocytes and cultured MCF-7 human breast cancer cells. Biochem. Pharmacol 2003;66:63-73.

9. De Mesquita, M.L., de Paula, J.E., Pessoa, C., De Moraes, M.O., Costa-Lotufo, L.V., Grougnet, R., Michel, S., Tillequin, F., Espindola, L.S.,. Cytotoxic activity of Brazilian Cerrado plants used in traditional medicine against cancer cell lines. J Ethnopharmacol 2007;123:439-45.

10. Bisset, N.G. Herbal Drugs and Phytopharmaceuticals - A Handbook for Practice on a Scientific Bases. London/Stuttgart, Medpharm/CRC Press. 1994.Pereira TS, de Santanna JR, Silva EL, Pinheiro AL, de CastroPrado MA. In vitro genotoxicity of Melaleuca alternifolia essential oil in human lymphocytes. $J$ Ethnopharmacol 2014;151(2):852-7.

11. Xia Liu, Yuangang Zu, Yujie Fu, Liping Yao, Chengbo Gu, Wei Wang, Thomas Efferth. Antimicrobial activity and cytotoxicity towards cancer cells of Melaleuca alternifolia (tea tree) oil. Eur Food Res Technol 2009;229:247.

12. CE Assmann et al. Tea tree oil presents in vitro antitumor activity on breast cancer cells without cytotoxic effects on fibroblasts and on peripheral blood mononuclear cells. Biomed Pharmacotherapy 2018;103:1253-61.

13. K. M. Arunasree, "Anti-proliferative effects of carvacrol on a human metastatic breast cancer cell line, MDA-MB 231," Phytomed 2010;17(8-9)581-588.

14. M. V. Sobral, A. L. Xavier, T. C. Lima, and D. P. de Sousa, "Antitumor activity of monoterpenes found in essential oils," Scientific World J 2014, Article ID 953451 